University of Nebraska - Lincoln

DigitalCommons@University of Nebraska - Lincoln

Management Department Faculty Publications

Management Department

2009

\title{
Organizational Narcissism and Virtuous Behavior
}

\author{
Dennis Duchon \\ University of Nebraska-Lincoln, dduchon2@unl.edu \\ Brian Drake \\ University of Texas at San Antonio, brian.drake@utsa.edu
}

Follow this and additional works at: https://digitalcommons.unl.edu/managementfacpub

Part of the Management Sciences and Quantitative Methods Commons

Duchon, Dennis and Drake, Brian, "Organizational Narcissism and Virtuous Behavior" (2009). Management Department Faculty Publications. 90.

https://digitalcommons.unl.edu/managementfacpub/90

This Article is brought to you for free and open access by the Management Department at DigitalCommons@University of Nebraska - Lincoln. It has been accepted for inclusion in Management Department Faculty Publications by an authorized administrator of DigitalCommons@University of Nebraska - Lincoln. 


\title{
Organizational Narcissism and Virtuous Behavior
}

\author{
Dennis Duchon, University of Tennessee, Knoxville \\ Brian Drake, University of Texas at San Antonio
}

\begin{abstract}
Extreme narcissistic organizations are unable to behave ethically because they lack a moral identity. While such organizations are not necessarily unethical intentionally, they become self-obsessed and use a sense of entitlement, self-aggrandizement, denial, and rationalizations to justify anything they do. Extreme narcissistic organizations might develop formal ethics programs, but such programs will have little effect on behavior.
\end{abstract}

Keywords: organizational narcissism, virtue

I think what I didn't understand when I was young was that corporations have personalities just like humans do. It is possible for companies to be virtuous.

- Larry Brilliant, Executive Director, Google.org

\section{Introduction}

Ethics is not missing from corporate life, but it can be obscured or marginalized (Roberts, 2001) by the character of the corporation itself. That is, a corporate system lacking a virtuous identity can manipulate and constrain moral agency (Nielsen, 2006). We define moral agency as the capacity (1) to make judgments about the goodness and badness of organizational behavior and (2) to take actions that comport with moral standards. However, rather than being the result of bad intentions or faulty judgments, unethical behavior can be a consequence of a corporation's self-concept; a consequence of how it defines itself.

Our argument is two-pronged. First, we argue that an organization's identity, operating as an ana- $\log$ to an individual's personality (Whetten, 2006), essentially determines whether or not that organization will be a moral agent (MacIntyre, 2007). Second we argue that organizations can adopt collective narcissistic identities that will produce wrong (i.e., non-virtuous) behavior. This happens because the organization's narcissistic identity-including the corresponding motive to protect its identity - is more powerful than a motive to behave morally.

\section{Organizational identities}

Organizations have identities. They are distinguishable; they have names, occupy physical space, and are accorded legal rights much the same as people. Whetton (2006) defines organizational identity as the "... central and enduring attributes of an organization that distinguish it from other organizations" (p. 220). These attributes allow the organization to legitimize and substantiate claims of uniqueness that has functional value in terms of its ability to both define a competitive domain and to present itself as an idealized actor within that domain (i.e., this is what we are; this is who we are). The attributes structure activity in the organization as shown in its core programs, policies and procedures, and they also provide a reference point for decision making and communication (i.e., this is what we do; this is how we do it). This reference point comes to be the foundation upon which the organization acts - an embodiment of its assumptions about the world and the organization's role in it. When the internally generated reference point acquires sufficient mass, it can partially or completely eclipse the reference point that prevails more broadly external to the organization. 
Within the boundaries of an identity, an organization develops distinctive preferences, commitments, and practices (Whetton, 2006) that reflect collectively shared assumptions or ideologies about its identity. That is, organizations develop belief systems or cultures that help the members understand behaviorally who they are as a collectivity, how they got that way, what they should be, and how they should behave (Hatch and Schultz, 2000; Schein, 1992; Trice and Beyer, 1993). An organization's identity emerges and is shaped as it solves adaptation and integration problems, and the organization's culture, as an analogue to personality, will find ways to display those central and enduring attributes that make up its identity. Culture is the social mechanism that will transfer the organization's identity to new members as the "correct" way to perceive, think, and feel (Schein, 1992, p. 4). As Trice and Beyer (1993) put it, being part of a culture means "...believing what others believe and doing as they do" (p.5). Among other central and enduring attributes, cultures develop distinctive mechanisms to cope with uncertainties (Trice and Beyer, 1993) and thus protect their identities.

Brown (1997) argues that collective entities have a need for self-esteem. Based on the work of Tajfel and Turner (cf. Tajfel, 1972; Tajfel and Turner, 1986; Turner, 1985), Brown contends that “... organizations consist in the common social identification of participating individuals acting as their organization, and that organizational self-esteem consists of the collective self-esteem of individuals acting as the organization" (1997, 649). Organizations, as social categories, exist in their members' common awareness of their membership, and so come to take on identities that are parts of their members' identities, needs, and behaviors. When organization members are motivated to preserve the part of their self-image derived from their social category, they are, collectively, regulating the self-esteem of the social category - the organization. Thus, the organization can regulate collective self-esteem with ego-defensive behaviors, not only to preserve identity, but also to enhance the legitimacy of the collective category (Brown, 1997).

Our notion of identity and regulation of collective self-esteem is consistent with an Institutional Theory view of organizations (cf. Powell and DiMaggio, 1991). Institutional Theory examines the processes by which structures including schemas, rules, norms, and routines become established as authoritative guidelines for social behavior. These processes are argued to be deep and resilient aspects of social structure (Scott, 2004). Social structures are then both imposed on and upheld by the actors within the structure. Thus, an institution becomes encoded into an actor through a socialization process and, once internalized, is transformed into a script of patterned behavior. When the actor behaves according to the script, the institution is enacted (Bjorck, 2004). Institutional Theory allows conceiving of an organization as exhibiting properties of supra-individual units of analysis that cannot be reduced to the direct consequences of an individual's attributes or motives (Powell and DiMaggio, 1991). Moreover, the institution will develop scripts, rules, and routines that are consistent with its identity and articulate what is and what is not ethical behavior.

\section{Moral identity}

Virtue Theory argues that morality is a function of an entity's character: What the entity is and has will enable dispositions to act in virtuous/unvirtuous ways (MacIntyre, 2007). Formal organizations can function like a moral person, and so be considered to possess an institutional character replete with institution- level virtues and vices (Moore and Beadle, 2006). Weaver (2006) has argued that entities, including organizations, can possess a network of moral traits rooted in self-concepts and manifested in actions. A moral identity exists when the entity is "...centrally oriented toward a collection of moral traits that both define (what) one is and yield tendencies toward paradigmatically moral action" (p. 345). Moral identity is subject to contextual influences and to the waxing and waning of its own salience, but its strength will match the degree to which it is a central part of the self concept.

Moral identity formed at higher levels capture cognitive schemas that direct thought and action and arrange people into roles (Weaver, 2006). These higherlevel identities influence the identities of lower-level entities such that organizational identities influence individual identities. For example, organizational identities influence the identities of business units, departments, groups, and ultimately individuals. The cognitive and symbolic order provided by the organization's identity both guides and delimits the be- 
havior of individuals acting on the organization's behalf. Thus, even though individuals or groups may be responsible for making decisions in organizations, those decisions will tend to be consistent with the larger system's moral identity (Weaver, 2006). Therefore, unethical behavior can emerge from organizations unintentionally, even without awareness. Unless virtue is a central part of the organization's self-concept, ethical behavior will never be considered an appropriate metric or standard to judge the outcomes of decisions.

\section{Organizational narcissism}

Narcissism is a term that generally connotes a person who possesses an extreme love of self, a grandiose sense of self-importance, and a powerful sense of entitlement. The American Psychiatric Association (2000) defines narcissism as a personality disorder characterized by "a pervasive pattern of grandiosity, need for admiration, and lack of empathy... and is present in a variety of contexts" (p. 717). The Manual suggests that narcissistic personality disorder is indicated by a person exhibiting a range of self-centered behaviors, 1 although a diagnosis of narcissistic personality disorder is somewhat imprecise and mostly the result of a clinician's judgment.

Narcissistic behaviors are generally seen as egodefense mechanisms used to bolster a fragile sense of self. Organizations, like people, are also motivated to protect their collective sense of identity and legitimacy, and, like people, can also sometimes engage in extreme narcissistic behavior. This narcissistic response is a coping mechanism intended to protect and preserve the organization's identity, but extreme manifestations can lead to dysfunction, even ruin. People in organizations can collectively get off-track in their efforts to protect the system's identity by behaving in ways that reinforce an exaggerated sense of system-self, and by ruthlessly exploiting both other organizations and members of their own system (Brown, 1997).

Organizations can create structures and processes (enduring attributes) that will reinforce and extend a sense of both identity and legitimacy (Brown, 1997; Ganesh, 2003). Such efforts to institutionalize identity are necessary to maintain the organization, and should be seen as normal; however, institutionalizing an extreme narcissistic identity can prove to be problematic. The extreme narcissistic organizational identity seeks to justify and legitimize itself at all costs, with scant reference to market accountability, civic responsibility, or ethical concerns (Ganesh, 2003). Extreme narcissists are entirely self-absorbed, out of touch, and not "reality based." The extreme narcissistic organization will institutionalize dominance, control, entitlement, and exploitation (Gregory, 1999) to reinforce its maladaptive identity. Thus, it is possible to observe organizational attributes and activities that can be used to label a system as an extreme narcissist, although notions of virtue and ethical behavior likely will not be among those attributes.

For example, Stein (2003) suggests that extreme organizational narcissism will possess five characteristic attributes. First, members of a narcissistic organization will believe their organization to be extraordinarily special and unique. This belief does not reflect normal feelings of pride and accomplishment, but is instead highly exaggerated to the point of delusion. Second, a powerful sense of self aggrandizement and entitlement leads to a kind of unconscious imperialism or an unconscious omnipotence: The organization is all powerful and anything of potency is felt to legitimately belong to it. Such an organization cannot recognize that anything of value might exist outside its boundaries. Third, the organization believes itself to be omniscient; that is, it has access to all information, both internal and external, that is relevant to the organization. Fourth, the delusion of the narcissistic organization allows it not only to be dismissive of other organizations, people and information, but also to treat them with a kind of triumphant contempt. Fifth, these attributes are so pervasive that they become permanently embedded in organizational functioning (Stein, 2003).

Brown (1997) has argued that extreme narcissistic organizations use denial to cope with conflict and stress. For example, such organizations deny facts about themselves through spokespeople, annual reports, and myths. They develop plausible and acceptable justifications for their actions through rationalization. They self-aggrandize by endowing themselves with a sense of rightness and making claims of their uniqueness. This is done in myriad ways. For example, they commission flattering corporate histories; executives make speeches embedded with claims of uniqueness; and they deploy their office layouts and architecture as expressions 
of status, prestige, and vanity. Extreme narcissistic organizations aggressively use annual reports and media campaigns to promulgate self-serving explanations of their actions. They assume that they are entitled to continued success, and that they are entitled to exploit resources, people, and other organizations in the service of that success (Brown, 1997). Clearly, such extreme organization narcissists will not be inclined to engage in virtuous practice (MacIntyre, 2007).

\section{Organizational narcissism and misconduct}

Ketola (2006) has shown that an organization uses ego-defense mechanisms to protect the integrity of its personality, even at the expense of sacrificing the morality of its actions. It is more important for organizations to feel that they are moral persons than to face the immorality of their actions (Ketola, 2006, p. 149). Using data from an oil company trying to cope with an oil spill, Ketola elaborates on what she terms corporate psychological defense. When facing accusations of misconduct, organizations use denial, repression, and omnipotent fantasies to fend off dealing with the facts of their own actions. They use rationalizations to admit responsibility, but deny any harm resulting from their unethical behavior. They use excuses to avoid taking responsibility.

Stein (2003) has argued that the near collapse of Long Term Capital Management (LTCM) in 1998 was caused not by a lack of information or poor decision processes, but by its own narcissism. LTCM's partners displayed denial of reality in believing that they possessed knowledge and capabilities far beyond those of any other hedge-fund managers. They believed themselves to be both omnipotent and omniscient, and this belief manifested itself at the sociotechnical core of the firm, where decisions were based on a belief that LTCM's Value at Risk calculations allowed it to predict and control the future. This led the partners to display entitlement by taking enormous risks in areas of investment such as the Russian economy in which it had no previous experience. Between January and August 1998, LTCM's leverage ratio reached 50:1 when 2:1 was the industry norm.

In their book about the fall of Arthur Andersen, Toffler and Reingold (2003) described how a once ethical corporate culture unraveled as it became in- creasingly narcissistic. Company founder, Arthur Andersen, was unfailingly clear about the need for a strong ethical culture. The company mantra was "think straight, talk straight," and a favored, cultureshaping story related how early in his career Andersen refused to approve an important client's inaccurate books. Andersen died in 1947, but his successors continued to cultivate a virtuous culture that valued integrity, trustworthiness, and ethical conduct. By the 1990s, however, the firm was growing and profitable because of its consulting business, not auditing, and the attitudes and values of the consulting side came to dominate. Although Toffler does not use the term "narcissism," she describes how a sense of entitlement, denial, self-aggrandizement, and rationalization replaced integrity and trustworthiness as the culture's core values, and those values translated into practices by which clients were routinely catered to and overcharged.

An important point here is that Toffler notes that the Arthur Andersen organization had formal ethical standards and ethics training. It even had a consulting group that helped other companies manage their ethics. But, inside the company, concern about ethics had pretty much disappeared. Narcissistically, the culture assumed itself to be ethical in all ways and therefore did not have "to worry about this stuff." At Arthur Andersen, just like its client Enron, a narcissistic identity predisposed the organizations toward unethical and illegal behavior. Neither system possessed a virtuous character.

Duchon and Burns (2007) have provided evidence that Enron itself possessed an extreme narcissistic identity, characterized by a sense of entitlement, self-aggrandizement, and denial. For example, Enron developed an organizational culture possessed of a powerful sense of entitlement where lavish, even wasteful, spending was seen as not merely normal, but necessary. Such spending was necessary to the extent it allowed the organization to protect and preserve its identity. The company installed itself in an architecturally grand (and expensive) building, and it was proud to pay $\$ 100$ million for the naming rights to the Houston Astros baseball team's stadium. Data and advice about bad decisions and faulty investments were routinely ignored or explained away. Illegal business practices became so much a part of everyday life that they essentially disappeared from the collective consciousness. 
Extreme narcissism was also displayed at Salomon Brothers in the 1980s, where both clients and employees were routinely exploited. For example, a reign of terror existed inside the company, where bond traders played on sales staff anxieties by regularly floating rumors that, in order to save money, all sales people would be fired. The sales staff themselves felt entitled to tell customers any kind of story in order to make a sale. Senior management felt entitled to seigniorial privileges. For example, they enjoyed a private elevator that only went to their floor in the building, and they only communicated with staff over the phone. Senior management also practiced a collective denial that all was well even though deregulation had thrown all of Wall Street into a tailspin (Duchon and Burns, 2007). The point is that both companies institutionalized a narcissistic identity that essentially gave permission for unethical and illegal behavior. Neither company survived.

\section{Why narcissism defeats formal ethics programs}

An organization's identity will shape its decision making processes and management practices by establishing what is normal, what is acceptable, and what is desirable: "this is what we are, this is what we do." Extreme narcissistic organizations develop self-obsessed identities such that collective self-aggrandizement, a profound sense of entitlement, and denial become normal. Such an identity makes cynicism, exploitation, and a lack of empathy acceptable. Such an identity is morally flawed: It does not contain a predisposition to act virtuously.

Ironically, extreme narcissistic organizations will likely establish formal ethics programs, although the programs will not have much effect on curbing unethical behavior. Formal ethics programs are an important aspect of self presentation; a way to show the world that the company is modern in every way. But Roberts (2001) has noted that only the appearance of ethical concern is important. So, driven by a need for self-aggrandizement, the extreme narcissistic organization will hire (expensive) consultants, create an elaborate program, and make sure the program receives much favorable comment in the press. The program will become a corporate bragging point; another way of proclaiming greatness. But, as Roberts (2001) notes, the "work of ethics" will go on purely at the surface, leaving the operational interior free to pursue its usual agenda.

But self-aggrandizement is not the only reason an extreme narcissistic organization might establish ethics programs. The program can be used exploitively as a kind of legal camouflage. The presence of such a program can by itself be used as a defense against accusations of unethical conduct, thus exploiting legal conventions. More importantly, the mere presence of the programs shifts the responsibility for ethical behavior away from cultural norms and onto the individuals who have been trained in the programs (Roberts, 2001). Ethical lapses can then be blamed on errant individuals, thus exploiting the system's own members. In either case the presence or absence of virtue is never questioned because such questions would be seen as attacks on the organization's identity. Exploitation was used to preempt such attacks.

Extreme narcissistic organizations want to appear ethical because appearing ethical feeds their narcissism, and so the costs of creating formal ethics programs are small compared to the ego-defense benefits. But such programs are instrumental for the narcissistic identity, not ethical conduct, and therefore will not much affect the behavioral status quo. Treviño and Brown (2004) have pointed out that ethics programs need to be part of a large, coordinated cultural system that supports ethical conduct everyday: Ethics "walk" needs to match ethics "talk." That is, ethics programs need to be part of a virtuous practice (Moore and Beadle, 2006), part of the essential character of the organization's identity.

\section{Discussion}

Extreme narcissistic organizations' cultures are excessively ego-centric and exploitive. Their membership will obsessively employ a sense of entitlement, self-aggrandizement, denial, and rationalizations to justify their behavior and so protect the collective's identity. Such organizations are not intentionally unethical - they are likely to have formal ethics programs - but concerns about ethical, or even legal, behavior will receive little more than lip service. Such cultures, like those at Enron, Salomon Brothers, or Arthur Andersen, can then drift into unethical or illegal behavior, and these behaviors be- 
come part of everyday life; they become normal. The organization then formally uses the defense mechanisms (rationalizations, denial, entitlement, etc.) to defend and justify its behavior because unethical behavior is now part of the collective identity ("this is who we are; this is what we do"), which must be preserved.

Once unethical behavior becomes institutionalized, individuals in the organization will, ironically, think of themselves as moral and continue their unethical behavior without pangs of conscience (Anand et al., 2005). To an outsider, these practices are obviously wrong, but insiders who have internalized the culture's logic cannot see anything wrong. Insiders see themselves and the behavior of the organizations they work for as good and right. To question or deny these propositions is to threaten the collective identity, which cannot be tolerated.

Extreme narcissistic organizations cannot behave ethically because they do not have a moral identity, i.e., a self-concept organized around a set of moral traits. Without a moral identity, an organization has no way to decide how to behave because Virtue Theory's essential question is "Who am I?," rather than "What principle should I follow?" Fundamentally, extreme narcissistic organizations do not possess a disposition of virtue.

In contrast to the extreme narcissist, however, it is possible for an organization to possess a virtuous character (Moore and Beadle, 2006). Such an organization would, first, be aware that it is founded on and sustains the particular business practice 2 it houses. The extreme narcissist loses sight of its essential practice as it becomes increasingly self-absorbed and defensive. Second, the virtuous organization encourages excellence in pursuit of its practice. Excellence means accepting the authority of standards and the inadequacy of one's own performance (MacIntyre, 2007), something the extreme narcissist is fundamentally incapable of doing. Third, the virtuous organization would focus on external goods (e.g., profit or reputation) as both a necessary and worthwhile function of the organization, but only to the extent necessary for the sustenance and development of the practice. The extreme narcissist so desires external goods that it will behave unethically to obtain them. Finally, the virtuous organization would be able to resist the corrupting power of institutions in its environment (Moore and Beadle, 2006). The extreme narcissist is the supreme exploiter and, as such, is itself a corrupt institution.

\section{Conclusion}

Some organizations enable unethical behavior because they lack a virtuous character. We have argued that an organization's identity (Whetten, 2006) essentially determines whether or not that organization will be a moral agent (MacIntyre, 2007). We also argued that organizations can adopt narcissistic identities that will produce wrong (i.e., non-virtuous) behavior.

Ethical behavior enacted from a deep sense of virtuous identity implies substantive rather than symbolic commitment to what Moore and Beadle (2006) term a "just purpose." For example, a virtuous organization develops a balanced power structure that ensures that the desires of particular constituencies are not privileged over others, thus dampening tendencies toward displays of entitlement. Decision making processes will enable rational, reality-based, critical dialogue to counter bias, rationalizations and denial. The organization will be characterized by displays of courage, justice, trust, and truthfulness (Moore and Beadle, 2006), and so counter self-aggrandizing displays. In contrast, an organization with an extreme narcissistic identity will be unable to realize, much less express, such substance. An extreme narcissistic organization is so focused on its own anxieties that it will be unable to articulate a just purpose.

Such an organization might devise rules in an attempt to approximate an ethical presentation, but this gesture is at best symbolic. The rules may address symptoms, but they will not confront the fundamental issue: the narcissistic identity. At worst, the rules feed and exaggerate the culture's preoccupation with itself by enabling excuses and wishful thinking. Consider that, over time, the formal ethics program residing within a narcissistic identity does not expose and remedy ethical lapses. Rather, it will "find" evidence that the organization in fact behaves ethically. In both the best, and worst cases, the organization with a narcissistic identity confuses the image of virtue with the authentic practice of virtue.

... Everyone seemed fixated on the same concept, which not coincidentally allowed them to declare 
victory. Just find the bad apples, punish them, and everything will be fine. This, I believe, is wishful and dangerous, if simple and direct, thinking. It precludes examining destructive corporate cultures and instituting real change.

-Toffler \& Reingold, Final Accounting, p. 229

\section{Notes}

1. The DSM-IV classifies someone who suffers from narcissistic personality disorder as having at least five of the following characteristics: (1) an exaggerated sense of selfimportance (e.g., exaggerates achievements and talents, expects to be recognized as superior without commensurate achievements); (2) Preoccupation with fantasies of unlimited success, power, brilliance, beauty, or ideal love; (3) Believes he is "special" and can only be understood by, or should associate with, other special or highstatus people (or institutions); (4) Requires excessive admiration; (5) Has a sense of entitlement; (6) Selfishly takes advantage of others to achieve his own ends; (7) Lacks empathy; (8) Is often envious of others or believes that others are envious of him; (9) Shows arrogant, haughty, patronizing, or contemptuous behaviors or attitudes.

2. The notion of practice comes from MacIntyre (2007). A practice is defined as "any coherent and complex form of socially established cooperative human activity through which goods internal to that form of activity are realized in the course of trying to achieve those standards of excellence which are appropriate to, and partially definitive of, that form of activity, with the result that human powers to achieve excellence, and human conceptions of the ends and goods involved, are systematically extended." (p. 187)

\section{References}

American Psychiatric Association: 2000, Diagnostic and Statistical Manual of Mental Disorders, 4th Edition. Text Revision (DSM-IV-TR) (American Psychiatric Association, Washington, DC).

Anand, V., B. E. Ashforth and M. Joshi: 2005, “Business as Usual: The Acceptance and Perpetuation of Corruption in Organizations," Academy of Management Executive 1, 9-23.

Bjorck, F.: 2004, "Institutional Theory: A New Perspective for Research into IS/IT Security in Organizations," Proceedings, 37th Annual Hawaii International Conference on System Sciences.

Brown, A. D.: 1997, "Narcissism, Identity, and Legitimacy," Academy of Management Review 22, 643-686.
Duchon, D. and M. Burns: 2007, “Organizational Narcissism," Proceedings, Southwest Academy of Management meeting, San Diego, CA.

Ganesh, S.: 2003, “Organizational Narcissism," Management Communication Quarterly 16, 558-595.

Gregory, B.: 1999, “The Impact of Narcissism on Leadership and Sustainability," in A. Cohill and J. Kruth (eds.), Pathways to Sustainability: The Age of Transformation (published on-line at http://www.ceres.ca.gov/tcsf/pathways/index.html by the Tahoe Center for a Sustainable Future, 1999).

Hatch, M. J. and M. Schultz: 2000, "Scaling the Tower of Babel: Relational Differences Between Identity, Image, and Culture in Organizations," in M. Schultz, M. J. Hatch and M. L. Larson (eds.), The Expressive Organization: Linking Identity, Reputation, and the Corporate Brand (Oxford University Press, New York).

Ketola, T.: 2006, "Corporate Psychological Defences: An Oil Spill Case," Journal of Business Ethics 65, 149-161.

MacIntyre, A.: 2007, After Virtue, 3rd Edition (University of Notre Dame Press, Notre Dame, IN).

Moore, G. and R. Beadle: 2006, "In Search of Organizational Virtue in Business: Agents, Goods, Practices, Institutions and Environments," Organization Studies 27(3), 369-389.

Nielsen, R. P.: 2006, “Introduction to the Special Issue. In Search of Organizational Virtue: Moral Agency in Organizations," Organization Studies 27(3), 317-321.

Powell, W. and P. DiMaggio: 1991, The New Institutionalism in Organizational Analysis (University of Chicago Press, Chicago).

Roberts, J.: 2001, "Corporate Governance and the Ethics of Narcissus," Business Ethics Quarterly 11, 109-127.

Schein, E. H.: 1992, Organizational Culture and Leadership, 2nd Edition (Jossey-Bass, San Francisco).

Scott, W.: 2004, "Institutional Theory," in G. Ritzer (ed.), Encyclopedia of Social Theory (Sage, Thousand Oaks, CA).

Stein, M.: 2003, “Unbounded Irrationality: Risk and Organizational Narcissism at Long Term Capital Management," Human Relations 56, 523-538.

Tajfel, H.: 1972, “La Categorisation Sociale," in S. Moscovici (ed.), Introduction a la Psychologie Sociale (Larousse, Paris).

Tajfel, H. and J. C. Turner: 1986, "The Social Identity Theory of Intergroup Behaviour," in S. Worchel and W. G. Austin (eds.), Psychology of Intergroup Relations (NelsonHall, Chicago).

Toffler, B. and J. Reingold: 2003, Final Accounting: Ambition, Greed, and the Fall of Arthur Anderson (Broadway Books, New York). 
Treviño, L. K. and M. E. Brown: 2004, “Managing to be Ethical: Debunking Five Business Ethics Myths," Academy of Management Executive 18, 69-81.

Trice, H. M. and J. M. Beyer: 1993, The Cultures of Work Organizations (Prentice-Hall, Englewood Cliffs, NJ).

Turner, J. C.: 1985, "Social Categorization and Self Concept: A Social Cognitive Theory of Group Behavior," Advances in Group Processes 2, 77-122.
Weaver, G. R.: 2006, “Virtue in Organizations: Moral Identity as a Foundation for Moral Agency," Organization Studies 27(3), 341-368.

Whetten, D. A.: 2006, "Albert and Whetten Revisited: Strengthening the Concept of Organizational Identity," Journal of Management Inquiry 15, 219-234. 